\title{
The Comb Sign
}

\section{Nathan S. Hill, David J. DiSantis}

Dept. of Radiology, University of Kentucky College of Medicine, Room HX-315B 800 Rose Street, Lexington, KY 40536, USA

\section{Classics in Abdominal Imaging}

\section{The Comb Sign}

20 years ago, Abdominal Imaging editor Morton Meyers described a CT sign now firmly in the radiology lexicon. He observed that, on contrast enhanced CT, the parallel engorged mesenteric vessels that supply bowel afflicted with active Crohn's disease resemble the parallel teeth of a comb (Fig. 1). Thus, the "Comb Sign" was born.

The sign is thought to reflect acute exacerbation of Crohn's Disease, showing straightening and dilation of the vasa recta to the inflamed bowel segment. The vessels are separated by mesenteric fat proliferation, a presumed response to more chronic inflammation (Fig. 2) [1].

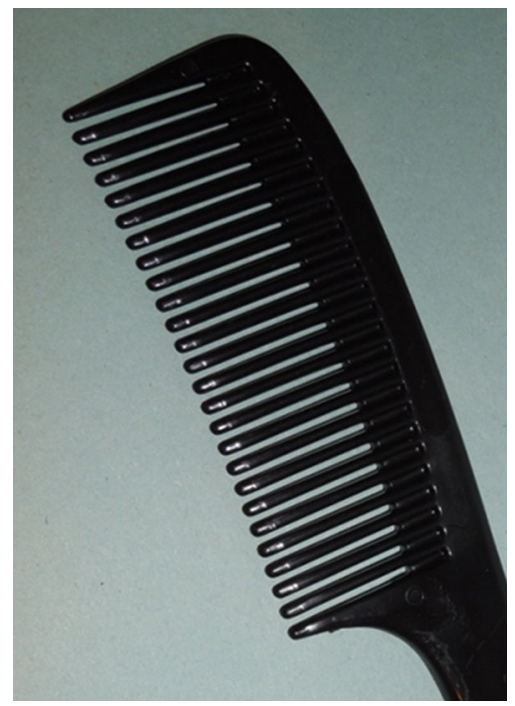

Fig. 1. Parallel teeth of a standard hair comb.

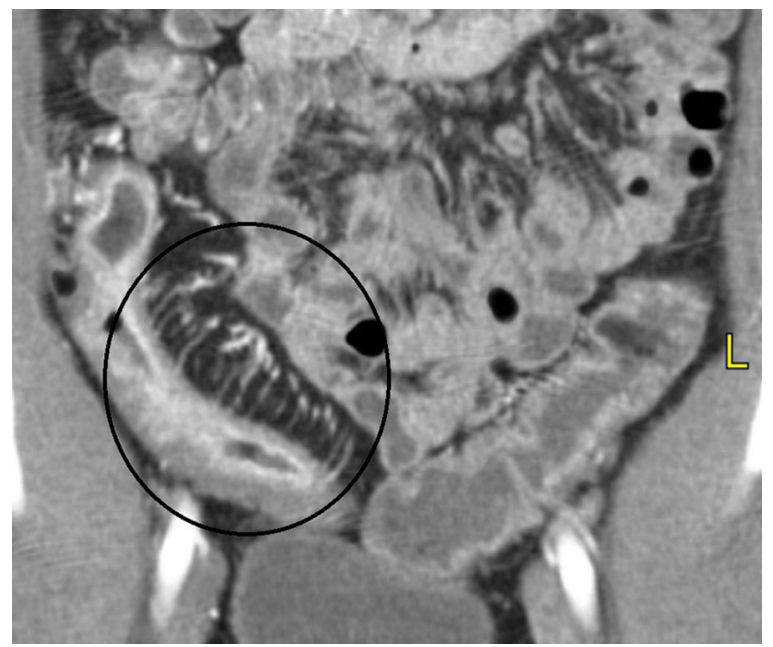

Fig. 2. Coronal contrast enhanced CT view depicting the imaging namesake: parallel vasa recta supplying an ileal segment with active Crohn's Disease. (Image courtesy of Raymond Dyer, MD).

While not specific to Crohn's disease, the presence of the comb sign helps in assessing the acuity of bowel inflammatory processes, and in differentiating them from neoplasms such as lymphoma or metastases [2].

\section{References}

1. Meyers MA, McGuire PV (1995) Spiral CT demonstration of hypervascularity in Crohn disease: "vascular jejunization of the ileum" or the "comb sign". Abdominal Imaging 20(4):327-332

2. Gore RM, Levine MS, eds. (2008) Textbook of Gastrointestinal Radiology. Saunders. Philadelphia, 1094. 